\title{
Canagliflozin improves obesity and insulin resistance in a diabetic patient with Cushing's disease undergoing postoperative steroid therapy: A case report
}

\author{
KOTA NISHIHAMA ${ }^{1}$, NORIKO FURUTA ${ }^{1}$, KANAKO MAKI $^{1}$, YUKO OKANO ${ }^{1}$, REI HASHIMOTO ${ }^{1}$, \\ YASUHIRO HOTTA ${ }^{1}$, MEI UEMURA ${ }^{1}$, TARO YASUMA ${ }^{2}$, TOSHINARI SUZUKI ${ }^{1}$, \\ CORINA N. D'ALESSANDRO-GABAZZA ${ }^{2}$, YUTAKA YANO ${ }^{1}$ and ESTEBAN C. GABAZZA ${ }^{2}$ \\ ${ }^{1}$ Department of Diabetes, Metabolism and Endocrinology, Mie University Graduate School of Medicine; \\ ${ }^{2}$ Department of Immunology, Mie University Graduate School of Medicine, Tsu, Mie 514-8507, Japan
}

Received November 14, 2017; Accepted September 13, 2018

DOI: $10.3892 / \mathrm{br} .2018 .1153$

\begin{abstract}
A 47-year-old woman with diabetes treated with high-dose insulin was admitted to Mie University Hospital, Tsu, Japan, for screening of secondary diabetes mellitus and obesity. Laboratory tests and imaging studies were consistent with Cushing's disease (CD). The patient underwent transsphenoidal pituitary surgery. The patient exhibited loss of body weight ( 85.9 to $80.0 \mathrm{~kg}$ ), improved glycated hemoglobin (HbA1c) (11.2 to 7.8\%) and required lower doses of insulin (112 to $46 \mathrm{U} /$ day) 6 months after surgery. The patient's body weight and daily insulin dose remained stable during the following 5 months (6-11 months after surgery). At that point, the patient was administered with canagliflozin, a sodiumglucose cotransporter 2 inhibitor. The patient required lower daily insulin dose without decreasing the dose of postoperative hydrocortisone concurrent to the administration of canagliflozin (100 mg/day). The patient's body weight decreased to $69.5 \mathrm{~kg}$ and withdrawal of insulin therapy was possible 8 months after initiation of canagliflozin. Despite withdrawal of insulin therapy, the HbA1c levels remained at $<7.0 \%$. Although surgical treatment is the first-choice treatment for $\mathrm{CD}$, obesity-related metabolic disorders including diabetes are frequent in $\mathrm{CD}$ patients following surgery. Canagliflozin may be an effective treatment to reduce body weight and improve insulin resistance following surgical treatment of CD.
\end{abstract}

Correspondence to: Dr Esteban C. Gabazza, Department of Immunology, Mie University Graduate School of Medicine, 2-174 Edobashi, Tsu, Mie 514-8507, Japan

E-mail: gabazza@doc.medic.mie-u.ac.jp

Key words: sodium-glucose cotransporter 2 inhibitor, Cushing's disease, obesity, insulin resistance

\section{Introduction}

Cushing's syndrome (CS) describes a group of metabolic disorders including Cushing's disease (CD) that are caused by oversecretion of adrenocortical steroids (1). Corticotropic adenomas secreting adrenocorticotropic hormone (ACTH) are the most common cause of endogenous CS (1). Oversecretion of cortisol stimulated by ACTH leads to a variety of signs and symptoms of CD including acne, red cheeks, moon face, 'buffalo hump', thin skin, weight gain, a pendulous abdomen and swelling of the feet/legs (2). A population-based study in Denmark reported the annual incidence of $C D$ to be 1.2-1.7 cases per million of the population (3). However, it is possible that there are many undiagnosed cases of CS/CD with poorly controlled diabetes, arterial hypertension and/or osteoporosis, particularly among younger individuals (2). CS has been associated with increased risk of fatal cardiovascular disease and infection (4). Despite the established benefits of surgical treatment in $\mathrm{CS} / \mathrm{CD}$, the frequency of obesity-related metabolic disorders (hypertension, diabetes, impaired glucose tolerance, hypercholesterolemia) and the mortality rate of CD patients remain high following surgery $(5,6)$. The current report describes a case of $\mathrm{CD}$ that was difficult to treat for body weight and insulin resistance following surgery. Therapy with canagliflozin, a sodium-glucose cotransporter 2 (SGLT2) inhibitor, reduced body weight and the daily insulin dose requirement of the patient. SGLT2 inhibitors may reduce the daily insulin requirement in diabetic patients but there is little information on the clinical course of patients that exhibit successful reduction of daily insulin dose. This is the first reported case of $\mathrm{CD}$-associated diabetes that presented improvement in body weight and insulin resistance following therapy with an SGLT2 inhibitor.

\section{Case report}

The patient was admitted to Mie University Hospital, Tsu, Japan, in October 2014 for treatment of obesity and diabetes. The patient was a 47 -year-old obese woman with a 20 -year history of type 2 diabetes mellitus associated with hyper- 
tension and dyslipidemia. In the previous hospital (Mie National Hospital, Tsu, Japan), the subject exhibited $414 \mathrm{mg} / \mathrm{dl}$ blood glucose in a random glucose test [non-diabetic level: $<200 \mathrm{mg} / \mathrm{dl}$ (7)] that were difficult to control requiring high doses of insulin. The patient exhibited no diabetic nephropathy or retinopathy and was under a strict diet $(1,000 \mathrm{kcal} / \mathrm{day})$ and bicycle exercise therapy (30 $\mathrm{min} /$ day). The treatment that the patient was receiving was as follows: Insulin aspart 30 U/day (Novo Nordisk Pharma Ltd., Tokyo, Japan), insulin glargine 36 U/day (Eli Lilly Japan K.K., Kobe, Japan), metformin 1,500 mg/day (Sumitomo Dainippon Pharma Co., Ltd., Tokyo, Japan), sitagliptin $50 \mathrm{mg} /$ day (MSD K.K., Tokyo, Japan), voglibose $0.9 \mathrm{mg} /$ day (Towa Pharmaceutical Co., Ltd., Osaka, Japan), valsartan $80 \mathrm{mg} /$ day (Novartis Pharma K.K.) and rosuvastatin $5 \mathrm{mg} /$ day (AstraZeneca K.K., Osaka, Japan). The clinical findings on examination were as follows: Height, $155 \mathrm{~cm}$; body weight, $87.5 \mathrm{~kg}$, body mass index $36.4 \mathrm{~kg} / \mathrm{m}^{2}$ (definition of central obesity by International Diabetic Federation: $>30 \mathrm{~kg} / \mathrm{m}^{2}$ ) (8); blood pressure, $119 / 79 \mathrm{mmHg}$ [target blood pressure level in diabetic patients: <130/80 $\mathrm{mmHg}(9)]$; heart rate, 103 beats/min; body temperature, $36.4^{\circ} \mathrm{C}$. Physical examination identified central obesity with waist circumference $126 \mathrm{~cm}$ (cut-off value of International Diabetic Federation: $80 \mathrm{~cm}$ ) (8) and whitish striae. Laboratory data on admission including the following: Glycated hemoglobin (HbA1c), 11.2\% [reference range: 4.6-6.2\% (10)]; fasting blood glucose, $338 \mathrm{mg} / \mathrm{dl}$ [non-diabetic level: <126 mg/dl (7)]; plasma ACTH, $49.5 \mathrm{pg} / \mathrm{ml}$ [reference range: $7.2-63.3 \mathrm{pg} / \mathrm{ml}(11)$ ]; plasma cortisol, $21.1 \mu \mathrm{g} / \mathrm{dl}$ [reference range 6.4-21.0 $\mu \mathrm{g} / \mathrm{dl}$ (11)]; urinary free cortisol, $295.4 \mu \mathrm{g} / \mathrm{day}$ [reference range: $11.2-80.3 \mu \mathrm{g} /$ day (11)] (Table I). There was no diurnal variation in plasma cortisol concentration and no suppression of plasma cortisol concentration during an overnight $0.5 \mathrm{mg}$ dexamethasone suppression test (DST) performed for the diagnosis of CS (12). An overnight DST using a high dose of dexamethasone $(8 \mathrm{mg})$ demonstrated suppression of the plasma cortisol levels to less than half of the basal level. The plasma ACTH levels did not exhibit a $>50 \%$ increase at any time following $100 \mu \mathrm{g}$ corticotropin releasing hormone $(\mathrm{CRH})$ administration. In a thyrotropinreleasing hormone test, thyroid stimulating hormone exhibited a peak value of $10.34 \mu \mathrm{U} / \mathrm{ml}$ at $30 \mathrm{~min}$ [normal response: increase of $>5 \mu \mathrm{U} / \mathrm{ml}$ (13)]. In a luteinizing hormone-releasing hormone test, luteinizing hormone and follicle stimulation hormone exhibited peak values of $92.6 \mathrm{mU} / \mathrm{ml}$ (normal response: increase of $>10 \mathrm{mU} / \mathrm{ml}$ ) and $94.4 \mathrm{mU} / \mathrm{ml}$ (normal response: increase of $>2 \mathrm{mU} / \mathrm{ml}$ ) (13), respectively. In a growth hormone-releasing protein 2 test, growth hormone exhibited a peak value of $9.421 \mathrm{ng} / \mathrm{ml}$ at $15 \mathrm{~min}$ (criteria for severe adult growth hormone deficiency: values of $<9 \mathrm{ng} / \mathrm{ml}$ ) (14) (Table I). Magnetic resonance imaging (MRI) revealed a $12-\mathrm{mm}$ pituitary tumor with delayed enhancement in T1-weighted MRI (Fig. 1A). Based on the presence of central obesity, diabetes mellitus, hypertension, pituitary tumor on MRI and abnormal findings in endocrinal tests, excluding the results of the CRH test, a diagnosis of CD was made. The reported low sensitivity of the CRH test may explain why the test was negative (15). The patient was then remitted to the Neurosurgery Department for trans-sphenoidal pituitary surgery. The patient's hyperglycemia was treated with 112 U/day insulin the day before surgery and improved following the transsphenoidal pituitary surgery. The pathological findings of the resected specimen were consistent with the diagnosis of benign pituitary adenoma as evaluated by histological study and hematoxylin and eosin staining (Fig. 1B). The serum levels of ACTH and cortisol decreased 9 days after surgery (to $9.8 \mathrm{pg} / \mathrm{ml}$ and $2.4 \mu \mathrm{g} / \mathrm{dl}$, respectively).

Following surgery, the patient was treated with $30 \mathrm{mg} /$ day hydrocortisone with gradual tapering over 19 months. The dose of insulin was gradually reduced to avoid hypoglycemia via self-monitoring of blood glucose levels; the dose was reduced by 4-10 units/week at the discretion of the patient. Sitagliptin and voglibose were withdrawn following surgery. After 6 months the level of HbAlc was $<7.0 \%$ and patient body weight decreased from 85.9 to $80.0 \mathrm{~kg}$. The daily insulin dose was $46 \mathrm{U} /$ day during the postoperative period under selfmonitoring and outpatient follow-up. The patient's body weight and daily insulin dose remained stable over the following 5 months. Canagliflozin was administrated 11 months after surgery. Following the administration of $100 \mathrm{mg} /$ day canagliflozin the patient exhibited loss of body weight (to $69.5 \mathrm{~kg}$ ) and required less daily insulin dose (to 0 U/day). Therapy with insulin was withdrawn 19 months after the surgical procedure when HbA1c level was $<7.0 \%$. The dose of valsartan was decreased (from 80 to $40 \mathrm{mg} /$ day) 10 months after and was withdrawn 12 months after starting therapy with canagliflozin. Remission of the CD was confirmed 19 months after the pituitary adenoma resection. In the absence of hydrocortisone, the plasma level of ACTH was $9.0 \mathrm{pg} / \mathrm{ml}$ and that of cortisol was $4.9 \mu \mathrm{g} / \mathrm{dl}$. The body weight of the patient was $55.3 \mathrm{~kg}$ and the HbAlc level was 5.8\% 31 months after the surgical procedure. This overall clinical course is depicted in Fig. 1C.

\section{Discussion}

CS including CD is characterized by metabolic disorders such as obesity and insulin resistance that are caused by overproduction of steroid hormones (2). CD is associated with a high rate of mortality caused by ischemic coronary artery disease and/or infectious diseases; a recent review article reported that standardized mortality ratios of CD ranged from 1.84 to 4.25 including global retrospective analysis (16). Surgical resection of pituitary adenoma is the first-line treatment for CD but not all patients with CS exhibit improvement in metabolic function following surgical treatment (17). Obesity and diabetes are particularly difficult to control, and the amount of inter-muscular adipose tissue remains unchanged following surgery $(5,18)$. Nevertheless, the present case exhibited loss of body weight and required lower daily insulin dose in the immediate postoperative period, and these signs remained stable 6 months after surgery.

Management of metabolic disorders in the postoperative period for patients with $\mathrm{CD}$ undergoing steroid therapy is a challenge. The present case required a relatively long period for withdrawal of steroid administration following surgery. Weight gain is accelerated during steroid therapy as glucocorticoids promote glucose production by the liver, peripheral glucose uptake in muscle and adipose tissues, and inhibit insulin production and secretion in pancreatic $\beta$-cells $(19,20)$. Body weight and the daily insulin dose of the current patient remained 

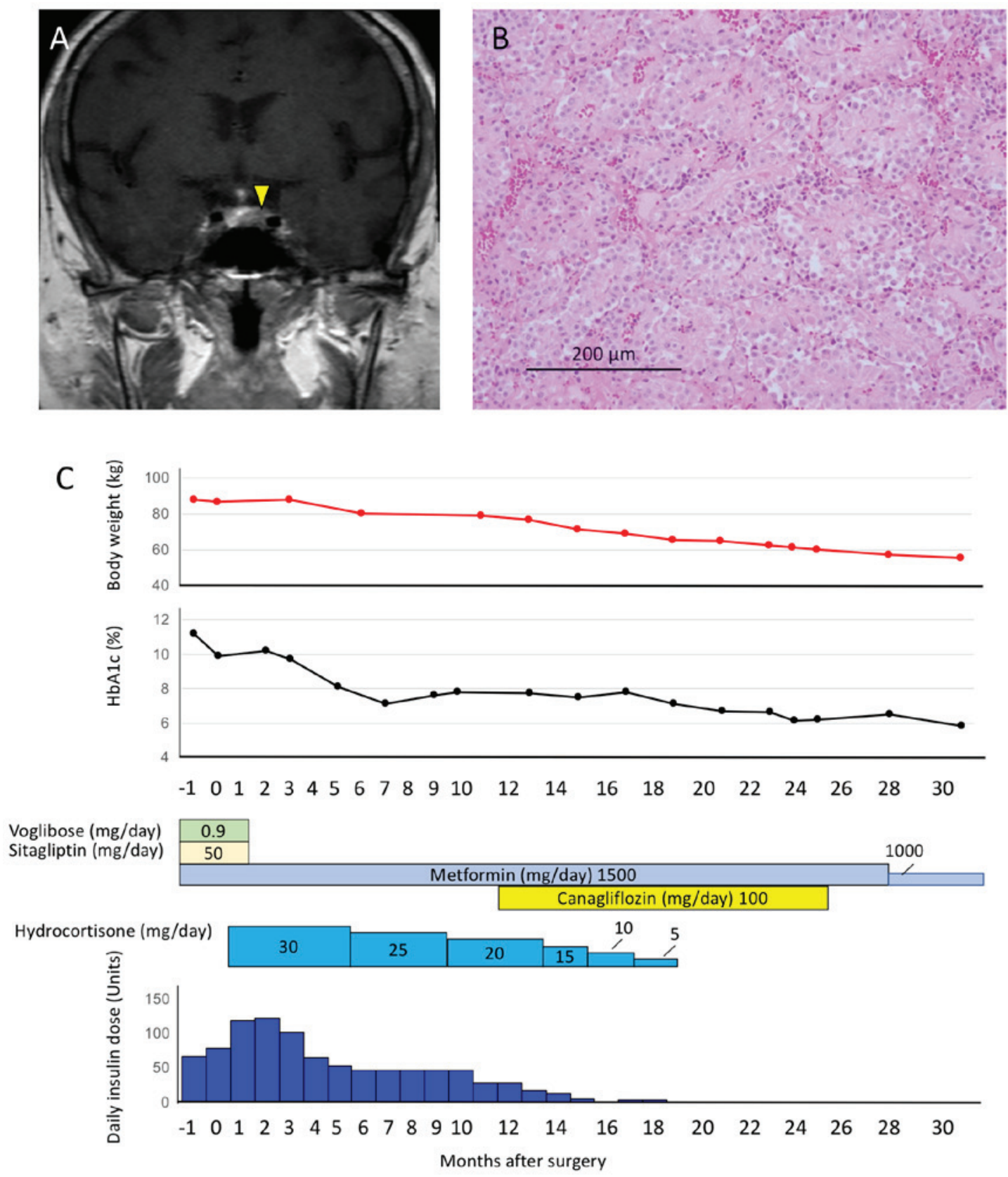

Figure 1. MRI, pathological examination and clinical course. (A) Late enhanced T1-weighted MRI revealed a 12-mm pituitary tumor (arrow). (B) Hematoxylin and eosin staining of resected specimens disclosed tumor cells with round or oval nuclei and pale eosinophilic cytoplasm (magnification, x20) consistent with the diagnosis of benign pituitary adenoma. Scale bar, $200 \mu \mathrm{m}$. (C) Reduction in body weight and requirement of lower insulin dose ceased at 6 months after transsphenoidal pituitary surgery, but further improved following initiation of canagliflozin. MRI, magnetic resonance imaging; HbAlc, glycated hemoglobin.

stable with no improvement between the sixth and eleventh month of the postoperative period. Initiation of canagliflozin, a sodium glucose co-transporter inhibitor, led to decreased body weight and lower requirement of insulin dose; complete insulin withdrawal and a body weight loss of $24.7 \mathrm{~kg}$ were observed 8 months after initiating therapy with canagliflozin.

To the best of our knowledge, this is the first report on the therapeutic effect of a sodium glucose co-transporter inhibitor in a CD patient post-surgery. The markedly beneficial effect of canagliflozin on body weight and diabetes in the postoperative period of the present patient whilst undergoing steroid therapy may be explained by the accelerated excretory activity of carbohydrates induced by the drug. Although data supporting the beneficial effects of SGLT2 inhibitor in glucocorticoid- related metabolic disorders is limited, studies on the mechanism of action of the drug suggest its potential favorable activity (21-23). Glucocorticoids increase the expression of sodium-dependent glucose cotransporters 1 and 2 by promoting the activity of serum- and glucocorticoid-inducible kinases; canaglifozin may suppress the effects of both sodium-dependent glucose cotransporters (21). An alternative explanation for the beneficial effect of canagliflozin is its stimulatory activity on the AMP-activated protein kinase, which may increase insulin sensitivity by activating intracellular signal pathways and decrease body weight by promoting energy consumption in adipose tissues (22). Therefore, it is conceivable that canagliflozin counteracted the inhibitory effect of glucocorticoids on AMP-activated protein kinase in 


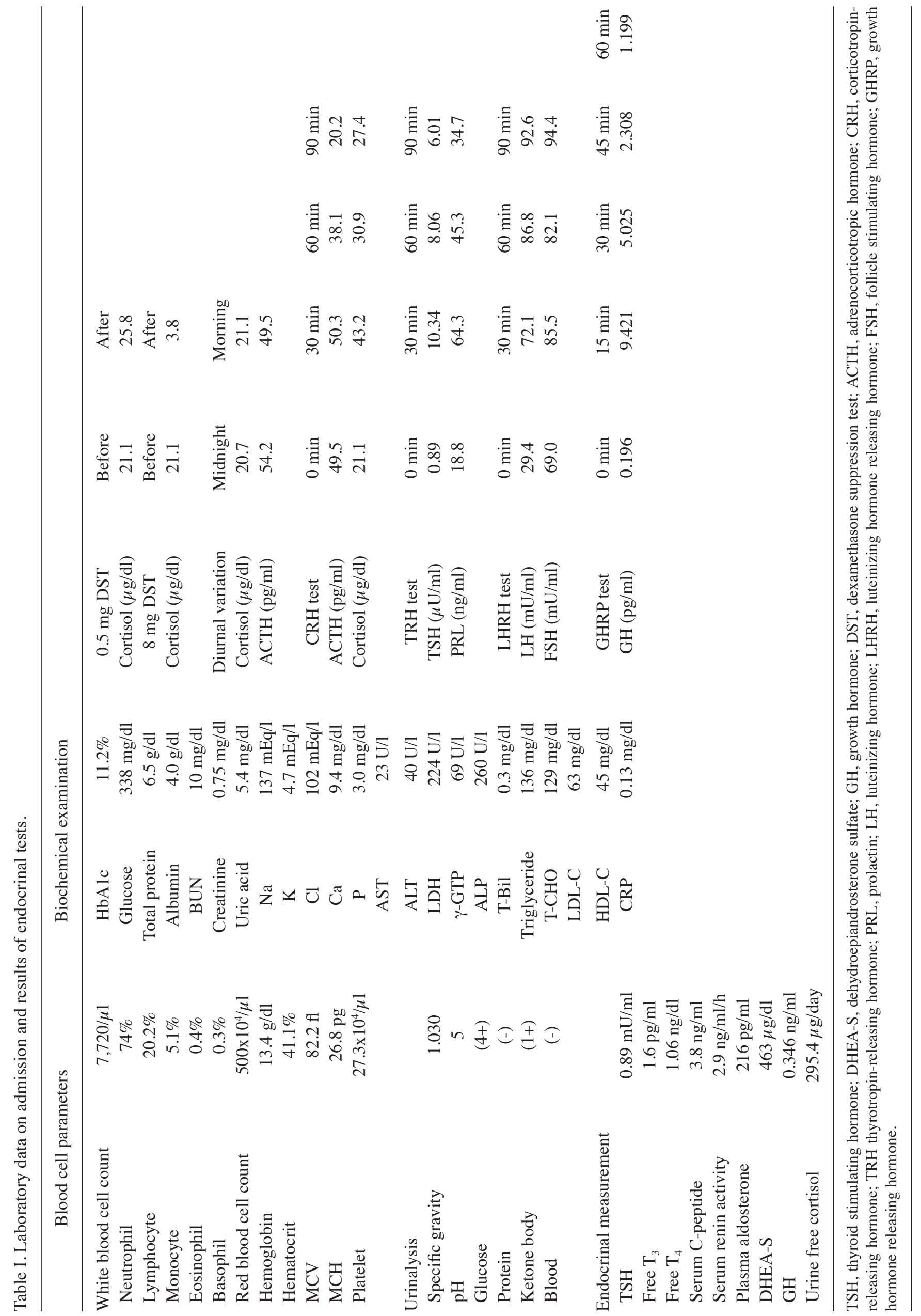


the adipose tissues of the current $\mathrm{CD}$ patient undergoing steroid therapy during the postoperative period (23).

It is noteworthy that the use of SGLT2 inhibitor in the early post-operative period may be detrimental since it may cause profound diuresis, which eventually may result in increased predisposition for deep vein thrombosis and hypotension due to decreased intravascular volume (24-26). Therefore, careful monitoring of the patient condition is required when SGLT2 inhibitor is used after surgery.

The present report demonstrates the potential of canagliflozin for the management of diabetic patients receiving steroids following surgical therapy for CD. However, it is noteworthy that other agents including glucagon-like peptide-1 agonists may also have similar beneficial effects on weight reduction in $\mathrm{CD}$ (27). The use of HbAlc alone and the lack of a glucose tolerance test to confirm the diabetic condition are limitations of the present case report. The blood glucose levels of the patient were measured during consultation at the outpatient department. However, the blood glucose levels measured during follow-up at the outpatient department are usually variable depending on the time from the last meal. Pasireotide has become available for the treatment of CD caused by pituitary adenoma (28). Pasireotide was not used in the present case since this medication has not been officially approved in Japan and the tumor was completely removed.

Despite the beneficial effects of canagliflozin observed in the current report, further data are required to demonstrate the effectiveness of SGLT2 inhibitor in CS patients with diabetes.

\section{Acknowledgements}

Not applicable.

\section{Funding}

Not applicable.

\section{Availability of data and materials}

Patient data and the clinical course were retrieved from electronic medical records.

\section{Authors' contributions}

$\mathrm{KN}$ was responsible for clinical treatment, follow-up, and preparation of the first draft of the manuscript. NF, KM, YO, RH, YH, MU, TY, TS and YY were responsible for clinical treatment, follow-up and interpretation of the data. CDG and ECG were responsible for interpretation of the data and intellectual contribution in the preparation of the manuscript.

\section{Ethics approval and consent to participate}

Not applicable.

\section{Patient consent for publication}

Written informed consent was obtained from the patient for the publication of clinical details and images.

\section{Competing interests}

The authors declare no competing interests.

\section{References}

1. Newell-Price J, Bertagna X, Grossman AB and Nieman LK: Cushing's syndrome. Lancet 367: 1605-1617, 2006.

2. Colao A, Boscaro M, Ferone D and Casanueva FF: Managing Cushing's disease: The state of the art. Endocrine 47: 9-20, 2014.

3. Lindholm J, Juul S, Jørgensen JO, Astrup J, Bjerre P, FeldtRasmussen U, Hagen C, Jørgensen J, Kosteljanetz M, Kristensen L, et al: Incidence and late prognosis of Cushing's syndrome: A population-based study. J Clin Endocrinol Metab 86: 117-123, 2001.

4. Nieman LK, Biller BM, Findling JW, Murad MH, Newell-Price J, Savage MO and Tabarin A; Endocrine Society: Treatment of Cushing's Syndrome: An Endocrine Society Clinical Practice Guideline. J Clin Endocrinol Metab 100: 2807-2831, 2015.

5. Chanson P and Salenave S: Metabolic syndrome in Cushing's syndrome. Neuroendocrinology 92 (Suppl 1): 96-101, 2010.

6. Hassan-Smith ZK, Sherlock M, Reulen RC, Arlt W, Ayuk J, Toogood AA, Cooper MS, Johnson AP and Stewart PM: Outcome of Cushing's disease following transsphenoidal surgery in a single center over 20 years. J Clin Endocrinol Metab 97: 1194-1201, 2012.

7. American Diabetes Association: 2. Classification and Diagnosis of Diabetes: Standards of Medical Care in Diabetes-2018. Diabetes Care 41 (Suppl 1): S13-S27, 2018.

8. Alberti KG, Zimmet P and Shaw J: Metabolic syndrome - a new world-wide definition. A Consensus Statement from the International Diabetes Federation. Diabet Med 23: 469-480, 2006.

9. Kai H: Blood pressure management in patients with type 2 diabetes mellitus. Hypertens Res 40: 721-729, 2017.

10. Little RR and Rohlfing CL: The long and winding road to optimal HbA1c measurement. Clin Chim Acta 418: 63-71, 2013.

11. Iwayama H, Hirase S, Nomura Y, Ito T, Morita H, Otake K, Okumura A and Takagi J: Spontaneous adrenocorticotropic hormone $(\mathrm{ACTH})$ normalisation due to tumour regression induced by metyrapone in a patient with ectopic ACTH syndrome: Case report and literature review. BMC Endocr Disord18: 19, 2018.

12. Kageyama K, Oki Y, Sakihara S, Nigawara T, Terui K and Suda T: Evaluation of the diagnostic criteria for Cushing's disease in Japan. Endocr J 60: 127-135, 2013.

13. Melmed S and Jameson JL: Hypopituitarism. In: Harrison's Principles of Internal Medicine. 19th edition. McGraw-Hill Education, New York, NY, pp2255-2261, 2015.

14. Fukuda I, Hizuka N, Nuraoka T and Ichihara A: Adult growth hormone deficiency: Current concepts. Neurol Med Chir (Tokyo) 54: 599-605, 2014.

15. Newell-Price J, Morris DG, Drake WM, Korbonits M, Monson JP, Besser GM and Grossman AB: Optimal response criteria for the human $\mathrm{CRH}$ test in the differential diagnosis of ACTH-dependent Cushing's syndrome. J Clin Endocrinol Metab 87: 1640-1645, 2002.

16. Pivonello R, De Martino MC, De Leo M, Simeoli C and Colao A: Cushing's disease: The burden of illness. Endocrine 56: 10-18, 2017.

17. Pivonello R, De Leo M, Cozzolino A and Colao A: The Treatment of Cushing's Disease. Endocr Rev 36: 385-486, 2015.

18. Geer EB, Shen W, Strohmayer E, Post KD and Freda PU: Body composition and cardiovascular risk markers after remission of Cushing's disease: A prospective study using whole-body MRI. J Clin Endocrinol Metab 97: 1702-1711, 2012.

19. Bouclaous C, Torbay N, Nassar C and Hwalla N: Modification of glucocorticoid effects on body weight gain, plasma lipids by changes in diet composition. Nutr Res 23: 1105-1115, 2003.

20. Tamez-Pérez HE, Quintanilla-Flores DL, RodríguezGutiérrez R, González-González JG and Tamez-Peña AL: Steroid hyperglycemia: Prevalence, early detection and therapeutic recommendations: A narrative review. World J Diabetes 6: 1073-1081, 2015.

21. Sopjani M, Alesutan I, Wilmes J, Dërmaku-Sopjani M, Lam RS, Koutsouki E, Jakupi M, Föller M and Lang F: Stimulation of $\mathrm{Na}^{+} / \mathrm{K}^{+}$ATPase activity and $\mathrm{Na}+$ coupled glucose transport by $\beta$-catenin. Biochem Biophys Res Commun 402: 467-470, 2010. 
22. Hawley SA, Ford RJ, Smith BK, Gowans GJ, Mancini SJ, Pitt RD, Day EA, Salt IP, Steinberg GR and Hardie DG: The $\mathrm{Na}^{+} /$glucose cotransporter inhibitor canagliflozin activates AMPK by inhibiting mitochondrial function and increasing cellular AMP Levels. Diabetes 65: 2784-2794, 2016.

23. Kola B, Christ-Crain M, Lolli F, Arnaldi G, Giacchetti G, Boscaro M, Grossman AB and Korbonits M: Changes in adenosine 5'-monophosphate-activated protein kinase as a mechanism of visceral obesity in Cushing's syndrome. J Clin Endocrinol Metab 93: 4969-4973, 2008.

24. Kelly J, Hunt BJ, Lewis RR, Swaminathan R, Moody A, Seed PT and Rudd A: Dehydration and venous thromboembolism after acute stroke. QJM 97: 293-296, 2004.

25. Yasui A, Lee G, Hirase T, Kaneko T, Kaspers S, von Eynatten M and Okamura T: Empagliflozin induces transient diuresis without changing long-term overall fluid balance in Japanese patients with type 2 diabetes. Diabetes Ther 9: 863-871, 2018.
26. Gelbenegger G, Buchtele N, Schoergenhofer C, Roeggla M and Schwameis M: Severe hypernatraemic dehydration and unconsciousness in a care-dependent inpatient treated with empagliflozin. Drug Saf Case Rep 4: 17, 2017.

27. Andersen A, Lund A, Knop FK and Vilsbøll T: Glucagon-like peptide 1 in health and disease. Nat Rev Endocrinol 14: 390-403, 2018.

28. Cuevas-Ramos D, Lim DST and Fleseriu M: Update on medical treatment for Cushing's disease. Clin Diabetes Endocrinol 2: 16, 2016. 